\title{
JOHN MELVIN LAIRD
}

THE following notice has been received from the President of the Actuarial Society of America, concerning Mr John M. Laird, who was an Associate of the Institute:

LAIRD, John MeLvin, died on 20 June 1942, aged 57. He became an Associate in 1908. Upon graduation from the University of Toronto in 1906 he entered the service of the London Life Insurance Company, London, Canada. In 1910 he joined the actuarial staff of the Connecticut General Life Insurance Company, Hartford, Connecticut, U.S.A., of which company he became Assistant Actuary in 1913, Actuary in 1917, Secretary in 1924, Vice-President in 1927 and a Director in 1936. Mr Laird was one of the foremost insurance executives in the United States. He was a Fellow of the Actuarial Society of America, which society he had served as Editor of its Transactions, Vice-President and President. He was a Fellow of the American Institute of Actuaries, and he had served as President of the American Life Convention. He was a Fellow of the American Casualty Actuarial Society. He contributed papers of unusual value on a wide variety of subjects to actuarial societies in America and to the International Congress. Despite his many business activities he found time and energy to assume many important civic and social responsibilities.

\section{On Active Service}

Kenneti Ernest Platt, Student, Pilot Officer, R.A.F. Killed in action, 18 April 1941 .

John Albert Stokes Banting, Associate, Pilot Officer, R.A.F.V.R. Killed, April 1942.

Petre Reginald Wright, Student, Sergeant Pilot, R.A.F. Killed, - 4 May 1942. 